\title{
EXPERIÊNCIA COM BLOGS: PERSPECTIVAS DE SOCIALIZAÇÃO DE HISTÓRIAS DE VIDAS DE MULHERES AFRODESCENDENTES E CRIANÇAS.
}

Originais recebidos em: 05/09/2011

Aceito para publicação em: 21/12/2012

Mônica Dias Vieira

Universidade do Estado de Santa Catarina movvieira@yahoo.com.br

Thaís Regina de Carvalho

Universidade do Estado de Santa Catarina thatahrc@gmail.com

Priscila Cristina Freitas

Universidade do Estado de Santa Catarina priskafreitas@hotmail.com

Neli Góes Ribeiro

Universidade do Estado de Santa Catarina neligoes@yahoo.com.br

Erro! Fonte de referência não encontrada.

Este artigo se refere a um projeto de extensão que vem sendo desenvolvido desde o ano de 2007 pelo Núcleo de Estudos Afro-Brasileiros (NEAB) da Universidade do Estado de Santa Catarina. A fim de ampliar seu público alvo, o referido projeto passou, no ano de 2010, por algumas alterações na metodologia e no título, passando a se chamar: Para Contar (Escrever) Outras Histórias. A partir dessa nova etapa, o projeto constituiu-se de duas ações: oficinas de elaboração de blogs com crianças de 10 a 12 anos e entrevistas com mulheres afrodescendentes da Associação de Mulheres Negras Antonieta de Barros (AMAB). As propostas aspiraram resgatar as histórias de vida, assim como valorizar aspectos da cultura afro-brasileira e da africana. $\mathrm{O}$ resultado obtido na ação realizada na Associação foi o registro de histórias de vida de mulheres afro-brasileiras que fazem parte de um grupo que traduz liderança, em suas comunidades, no campo religioso, também são ícones do carnaval. Já com as crianças proporcionamos o maior contato com a inclusão digital, através da construção de blogs, nos quais elas puderam relatar suas histórias, vivências e, assim, foram se identificando como sujeitos da sua própria história. Essa experiência nos permitiu destacar o uso de tecnologias como mediadoras do papel que nós, educadoras, temos: disponibilizar trabalhos diversificados e interdisciplinares em nossa prática.

Palavras-chave: Mulheres afrodescendentes;

Crianças; Cultura afro-brasileira; Tecnologias.

\section{EXPERIENCE WITH BLOGS: PERSPECTIVES \\ OF SOCIALIZATION OF LIFE STORIES OF \\ AFRO-DESCENDANTS OF WOMEN AND \\ CHILDREN.}

\begin{abstract}
This article refers to an extension project that has been developed since 2007 by the Center of Afro-Brazilian Studies - NEAB from University of State of Santa Catarina.

This project in 2010 has undergone some changes to expand the target audience as well changes in the methodology and the title, starting to be called: To Count (write) Other Stories.

From this new stage, it consists of two actions: workshops to draw up blogs with children aged 10 to 12 years and interviews with women african descent of the Association of Black Women Antonieta de Barros - AMAB. Proposals aspired to rescue the life stories as well as valuing aspects of Afro-Brazilian and African culture. Was obtained as a result of the action taken at the Association the record of life histories of women afro-Brazilians who are part of a group that translates into leadership in their communities, as well in the religious and carnaval icon. Have the children provide the most contact with the digital divide, in which blogs by building the children could tell their stories, experiences and were identifying themselves as agents of their own history. This experience has allowed us to highlight the technologies as mediators on which us educators have to provide diverse and interdisciplinary work in our practice.
\end{abstract}

Keywords: Women african descent; Children; Afro-Brazilian Culture; Technologies. 


\section{INTRODUÇÃO}

No ano de 2010, o "Projeto Para Contar (Escrever) Outras Histórias", integrante do Programa Diversidade Étnica na Educação, desenvolvido pelo Núcleo de Estudos AfroBrasileiros (NEAB) da Universidade do Estado de Santa Catarina (UDESC) realizou duas ações cujo objetivo central era o resgate de histórias de vida de mulheres negras e crianças. Sendo assim, participaram deste projeto mulheres integrantes da Associação de Mulheres Negras Antonieta de Barros $(\mathrm{AMAB})^{1}$ e um grupo composto por dez crianças, de 10 a 12 $\operatorname{anos}^{2}$, da Escola Básica Municipal Idelfonso Linhares ${ }^{3}$. As ações realizadas tiveram como premissa o combate ao racismo, às discriminações e aos preconceitos, assim como a valorização da mulher negra e de toda população afro.

Dessa forma, após delimitarmos o público alvo, com intuito de envolvê-lo de maneira efetiva durante as propostas, elencamos, como principais metodologias de trabalho, as entrevistas semiestruturadas ${ }^{4}$, observações participantes e oficinas pedagógicas. Cabe ressaltar que, por meio dessas ações, exploramos desde a importância da oralidade e da ancestralidade até da inclusão digital nas instituições de ensino. Nesse sentido, nos foi possibilitado, junto ao grupo de mulheres, recuperar histórias, narrativas, expressões culturais e relatos sobre a comunidade. Além disso, através da construção dos blogs com as crianças, constatamos o quanto uma aprendizagem participativa no ambiente escolar pode tornar as ações mais atrativas e interessantes, fazendo com que as crianças interajam mais na sala de aula.

\subsection{Breves discussões a respeito da utilização de ferramentas eletrônicas}

Pesquisadores(as) e extensionistas envolvidos(as) com a temática, de um modo geral, elencam que a utilização de ferramentas eletrônicas vem crescendo e ampliando o seu espaço a cada dia, sendo aproveitadas de diversas maneiras, desde a divulgação de eventos, materiais e trabalhos até momentos de interação e distração. Por meio dessa perspectiva, essas ferramentas atualmente estão sendo utilizadas por todas as faixas etárias, nos múltiplos espaços e com distintos interesses, podendo auxiliar de forma efetiva na disseminação de

\footnotetext{
${ }^{1}$ Localizada na Rua Djalma Moellmann, n. 164, Centro, Florianópolis/SC.

${ }^{2}$ As crianças foram selecionadas pela instituição, e as atividades ocorreram no período de contraturno.

${ }^{3}$ Localizada no bairro Carianos, Florianópolis/SC.

${ }^{4}$ As entrevistas foram realizadas por meio de gravações audiovisuais.
} 
informações. Portanto, a criação de blogs, tanto com o material produzido com mulheres quanto com as atividades e histórias das crianças, apresenta-se como estratégia essencial para divulgação e valorização das ações realizadas.

Entretanto, apesar de acreditarmos que a utilização de ferramentas eletrônicas pode auxiliar no processo de ensino e aprendizagem das crianças, pesquisas retratam que muitos(as) professores(as) têm receio de trabalhar com essas tecnologias. Segundo Schoninger (2010, p. 40), "alguns professores demonstram resistência e medo ao desconhecido, receio de não conseguir e por isso se fecham para as novas possibilidades que envolvam o uso de tecnologias em suas aulas".

Sobre esse receio de utilização da ferramenta, destacamos que ele pode estar relacionado ao atual perfil das crianças, já que os ciberespaços, que se baseiam em um novo meio de comunicação interconectado mundialmente por computadores (Lévy, 1999), estão muito presentes em seus cotidianos, por exemplo: Orkut, Twitter, Facebook, MSN e games, sendo que as crianças navegam tanto em suas residências quanto em espaços como Lan houses.

Segundo estudos, a utilização dessas mídias pelas crianças a cada dia aumenta mais, e junto a esse crescimento também surgem os múltiplos lugares de navegação, pois mesmo não possuindo acesso à internet em seus lares, elas procuram algum meio para entrar em contato com essas novas Tecnologias de Informação e Comunicação (TICs). Sendo assim, constatamos que mesmo que a criança não tenha computador em casa, ela pode ter acesso a ele em outros espaços e, assim, a escola também poderia/deveria ser um local de acesso. Nesse caso, o(a) educador(a) não deve se sentir pressionado(a), mas sim pensar em aliar a sua prática a um processo interdisciplinar com intuito de colaborar com o aprendizado de seu/sua aluno(a), bem como compreender que o acesso às novas tecnologias pode ser interpretado como um processo de democratização. Seguindo esse pressuposto, expomos as contribuições de Belloni (2011, p. 10) acerca da inserção das mídias na escola

[...] deve-se acrescentar uma outra mais geral e a mais importante de todas: a escola deve integrar as tecnologias de informação e comunicação porque elas já estão presentes e influentes em todas as esferas da vida social, cabendo à escola, especialmente à escola pública, atuar no sentido de compensar as terríveis desigualdades sociais e regionais que o acesso desigual a estas máquinas está gerando. 
A mesma autora ainda relata que, além de democratizar o acesso às máquinas, essas tecnologias já estão e estarão ainda mais presentes nas vidas das crianças, seja em uma eleição, seja nas empresas que futuramente poderão vir a trabalhar. E para que as crianças e jovens estejam preparados para utilizar essas ferramentas, é necessário que ocorra uma transformação profunda nos ambientes escolares, a qual vai desde a formação dos(as) professores(as) voltada a essas metodologias de ensino até o investimento de equipamentos, materiais didáticos. Além disso, torna-se fundamental a criatividade por parte dos mediadores(as), para que esses momentos não se transformem em meros preenchimentos de tempo, sem cunho pedagógico.

Nesse sentido, reiteramos a necessidade da programação e planejamento da utilização dessas ferramentas para que, de fato, as crianças, jovens e adultos possam usufruir dessas tecnologias, tanto na vida pessoal, quanto na escolar e profissional.

\section{COMO TUDO ACONTECEU}

Esta etapa será dedicada à exposição sucinta das estratégias utilizadas para realização das ações com as mulheres afrodescendentes da Associação de Mulheres Negras Antonieta de Barros e com as crianças do contraturno da Escola Básica Municipal Idelfonso Linhares. Em face ao público, programamos entrevistas e conversas com o grupo de mulheres e oficinas pedagógicas com as crianças.

\subsection{Conhecendo a ação na Associação de Mulheres Negras Antonieta de Barros}

Partindo do pressuposto de que ações que priorizam a valorização de sujeitos que são silenciados pela sociedade também contribuem para desmistificar determinados estereótipos e estigmas que são criados em torno de algumas culturas, o projeto "Para Contar (Escrever) Outras Histórias" foi ao encontro de mulheres afrodescendentes que participam de projetos sociais para que estas nos contassem aspectos das suas histórias de vida. 
A partir dessa perspectiva, participamos ${ }^{5}$, junto com as mulheres, das oficinas de fuxico e de terno de reis (cantoria) ${ }^{6}$, integrantes do projeto "Oficinas de Arte-Educação", promovidas pela Fundação Cultural de Florianópolis Franklin Cascaes (FCFFC).

Durante os momentos que vivenciamos com as mulheres, realizamos, entre os meses de março a julho de 2010, entrevistas com quatro pessoas ${ }^{7}$, sendo estas, na sua maioria, professoras e integrantes da associação. Sobre as questões abordadas nas entrevistas, ressaltamos que foram elaboradas de forma cronológica, a fim de serem abarcadas lembranças desde o nascimento até a vida profissional. Assim, foram abordados temas como: tipo de lazer na infância, encontros familiares, igreja, carnaval, ancestralidade, oralidade, trajetória escolar, festividades, representação/atuação na comunidade, formação, carreira profissional e experiências de militância no movimento negro.

\subsection{Conhecendo a ação na Escola Básica Municipal Idelfonso Linhares}

Em meio a experiências vivenciadas em cursos de formação continuada para professores(as) na modalidade a distância, enquanto organizadoras e tutoras, surgiu-nos a ideia de propor a inclusão dessas ferramentas também no ensino regular. Isto é, realizar a oficina Introdução ao Mundo Digital, a fim de criarmos blogs nos quais os/as participantes pudessem registrar suas experiências de vida.

Com relação à característica dos blogs, Primo (2008) conclui que muitos os definem como diários pessoais; contudo, existem autores(as) que os classificam como profissional e organizacional. No entanto, para Primo (2008), o blog nada mais é que um meio de comunicação.

Buscando evitar tais armadilhas, blogs pessoais serão aqui compreendidos como um, e apenas um, dos possíveis tipos de blogs. Trata-se de uma produção individual, mas que diferencia-se dos blogs profissionais, por não ser guiada por objetivos e estratégias bem definidos e em consonância com o trabalho do autor. Pelo contrário, as principais motivações que movem o blogueiro são o prazer de expressar-se e interagir com os outros. De toda forma, não se pode aceitar a proposta de que estes blogs se caracterizam necessariamente pela espontaneidade e sinceridade. Trata-se de

\footnotetext{
${ }^{5}$ Bolsista de Extensão, Mônica Dias Vieira, aluna da 6 a fase do curso de Pedagogia, e Priscila Cristina Freitas, bolsista voluntária e aluna da $5^{\mathrm{a}}$ fase do curso de Pedagogia.

${ }^{6}$ Essas oficinas tinham encontros semanais, sendo as de Fuxico realizadas nas quartas-feiras, e as de Terno de Reis, nas quintas-feiras.

${ }^{7}$ Foram entrevistadas a professora de fuxico e sua irmã e mais duas professoras integrantes da associação.
} 
outro postulado que busca encontrar uma certa "essência" do blogar. Um blog pessoal pode ser assinado pela identidade fictícia de um blogueiro (o chamado "fake"), constar de histórias ficcionais, rumores, piadas ou até mesmo funcionar como um repositório de informações encontradas em outros sites (p. 7).

Portanto, consideramos que os blogs criados neste projeto se enquadram no que Primo (2008) elenca como blog pessoal, visto que não visaram a fins lucrativos, nem faziam parte de uma empresa.

A partir desse contexto, realizamos, no mês de julho, cinco encontros com as crianças, totalizando uma oficina de vinte horas. Essa, por sua vez, foi subdividida em minioficinas semanais, nas quais desenvolvemos dinâmicas de integração, construção de fôlderes de apresentação e construção dos blogs. Nessa oficina, as crianças foram convidadas a contar as suas histórias de vida, informando com quem moravam e onde estudavam. Além disso, foi solicitado a elas que explicassem no blog o porquê de sua construção.

\section{ENTRE FUXICOS E BLOGS: RESULTADOS E ANÁLISES DAS AÇÕES}

As ações do projeto "Projeto Para Contar (Escrever) Outras Histórias", como já mencionado acima, tiveram como público alvo mulheres afrodescendentes e crianças do ensino regular da rede pública de Florianópolis. A seguir, relataremos algumas passagens das experiências vivenciadas com esses grupos.

\subsection{Fuxicos, cantorias e conversas: (re)conhecendo a história de vida de mulheres negras catarinenses}

Primeiramente, vale enfatizar que as ações vivenciadas com as mulheres da associação nos proporcionaram a ampliação dos conhecimentos acadêmicos e pessoais, visto que, no período de nossas visitas às oficinas de fuxico, tivemos o prazer de conhecer um pouco mais sobre as histórias das professoras, além de aprender a fazer o artesanato. Outro ponto fundamental a se reiterar foi a oportunidade única de (re)conhecermos um pouco mais a história de personagens negras que, embora invisibilizadas e silenciadas, tanto contribuem para a cultura local, através do fuxico, do carnaval, de rezas e de cantorias. 
A respeito do silenciamento e da necessidade de valorização da história e da cultura africana e afro-brasileira, Gomes (2008) afirma que

Essa revisão histórica do nosso passado e o estudo da participação da população negra brasileira no presente poderão contribuir também na superação de preconceitos arraigados em nosso imaginário social e que tendem a tratar a cultura negra e africana como exóticas e/ou fadadas ao sofrimento e à miséria. (p. 72).

Sendo assim, reitera-se que resgatar as histórias das personalidades afro faz com que crianças e adultos, independentemente de sua raça, etnia, classe ou gênero, compreendam que nossa sociedade é composta de diversas culturas. Além disso, outro ideal a se disseminar é o imperativo da importância de considerarmos e valorizarmos todas as culturas sem preconceitos e discriminações.

Nessa perspectiva, é válido expor trechos da entrevista realizada, no dia 16 de junho de 2010, com a professora de fuxico e sua irmã, na qual elas contaram sobre suas relações familiares, trabalhos, moradias, entre outros. Um ponto primordial a se ressaltar é que, a partir das entrevistas, podemos constatar quanto o racismo permeia a nossa sociedade, seja de forma velada, seja de forma explícita. De acordo com nossos registros (2010), as entrevistadas falaram sobre a relação com os pais e irmãos e sobre a vinda de Imbituba, cidade onde nasceram, para Florianópolis, tendo em vista que vieram trabalhar em casas de famílias. Cada uma foi para uma casa, onde trabalharam, por grande parte das suas vidas, como empregadas domésticas e, assim, foram construindo suas vidas. Comentaram também sobre festas, bailes, namoros, casamentos, filhos e a questão do preconceito, que não foi questionada por nós em nenhum momento, mas apareceu quando descreviam as festas em que participavam, visto que os clubes eram separados, ou seja, havia clubes frequentados apenas por negros, e outros somente por brancos. Lembrando que a época em que elas eram adolescentes e moças foi praticamente a década de cinquenta. (Diário de campo do dia 16/06).

Por meio desses depoimentos, percebemos a necessidade e importância de questões referentes ao racismo, preconceitos e discriminações serem denunciadas e problematizadas em todos os ambientes da sociedade, para que assim possamos criar e (re)pensar estratégias de combate que caminhem em busca de uma sociedade mais justa e igualitária. 
As outras entrevistadas ${ }^{8}$, também integrantes da AMAB, relataram sobre suas brincadeiras de infância, suas trajetórias escolares até chegar ao ensino superior e suas relações com o carnaval e com a comunidade da qual fazem parte. Em vista da importância e necessidade do reconhecimento e valorização das histórias de vida dessas mulheres, salientamos que as elas são personalidades reconhecidas na sua comunidade, ocupando papel de destaque tanto em escolas de samba como nos bancos escolares. Vale enfatizar que as entrevistadas foram professoras de pesquisadores(as) negros(as) catarinenses, servindo de incentivo e exemplo para que estes permanecessem e ascendessem nos estudos e respectivas carreiras.

Cabe publicar que, com intuito de divulgar esse trabalho, utilizamos blogs. Aspiramos, por meio destes, ampliar as comunicações e notícias acerca dos trabalhos realizados na associação, bem como socializar as entrevistas realizadas com as mulheres da AMAB. É válido expor que o programa usado para elaborar tanto blog da associação quanto o da atividade com o grupo de crianças é gratuito e de fácil acesso. Tal programa intitula-se "blogger"9.

Foram criados dois blogs: um com o mesmo nome do projeto (Para Contar (Escrever) Outras Histórias) cuja intenção era socializar todos os trabalhos que vêm sendo realizados pelas integrantes, e outro para propagar as ações desenvolvidas pelo grupo de mulheres da Associação de Mulheres Negras Antonieta de Barros (AMAB). Este blog recebeu o mesmo nome da associação. Através deles, conseguimos divulgar o trabalho das oficinas de fuxico, com o objetivo de mostrar os trabalhos e gerar renda para a associação.

Em relação às entrevistas realizadas com o grupo de mulheres, inicialmente pensávamos em transcrevê-las de modo integral para resgatarmos relatos de histórias de vida de mulheres negras catarinenses, visto que estas possuem muitas histórias sobre o carnaval, festas de igreja, o ingresso na escola, na faculdade e no trabalho. No entanto, após os encontros e início das transcrições, acordamos priorizar a publicação no blog dos artesanatos atrelados a alguns pontos abordados nas entrevistas, para futuramente organizarmos um material específico com as entrevistas, fotos e gravações de vídeo das mulheres da associação.

Ainda vale salientar que as intervenções propostas pelo projeto passaram por múltiplos processos de replanejamento, pois inicialmente pretendíamos resgatar histórias de vida de

\footnotetext{
${ }^{8}$ Cabe expor que, no decorrer do relatório, essas professoras foram chamadas de Profa. U. e V.

9 Pode ser criado no endereço: www.blogger.com.
} 
mulheres afrodescendentes de uma associação, com a intenção de registrar suas memórias em documentos, mas, durante os encontros, optamos por ampliar a ideia e publicar os momentos, artesanatos e relatos no blog "Associação de Mulheres Negras Antonieta de Barros". Acreditamos que essa iniciativa possibilitará a continuação da divulgação dos trabalhos, tornando-se um canal de socialização das ações realizadas na associação. Além disso, a ferramenta pode ser utilizada para disponibilizar artigos e outras produções realizadas pelas associadas, disseminando assim, seus trabalhos em toda a sociedade.

Podemos divulgar, através dos blogs, a história dessas mulheres, como também suas representações na sociedade, histórico da associação e os sujeitos que fazem parte dela. Dessa forma, almejando reconhecer e valorizar a militante Antonieta de Barros, dedicamos um espaço para retratar a sua importância e representação na sociedade. No blog da associação, conforme explícito anteriormente, contamos com os artesanatos elaborados pelas mulheres artesãs da oficina de fuxico.

A partir dessa proposta, salientamos a importância de também valorizarmos as ações de extensão enquanto produtoras de conhecimentos, já que, por meio delas, também é possível atrelar as teorias às vivências experienciadas.

\section{2 É hora de navegar: Relatos de uma experiência com inclusão digital}

No tocante às atividades feitas com as crianças, destacamos que foram surpreendentes, visto que a bolsista de extensão responsável pelas dinâmicas e pelo projeto imaginava inicialmente que, por se tratar de crianças, estas não teriam muitas histórias para registrar; todavia, com o passar dos dias e a cada história narrada, essa suposição não se reafirmou, o que levou a bolsista a perceber sua visão estereotipada acerca das vivências das crianças. A partir daí, em meio aos relatos, percebemos o quanto as crianças tinham para nos contar e publicar nos seus blogs, pois, mesmo com pouca idade, já experienciaram muitas vivências, chegando a surpreender as oficineiras, pois muitos fatos fugiam de suas realidades. Nesse sentido, enfatizamos a necessidade de uma relação dialógica na educação, de tal maneira que profissionais e crianças possam compartilhar suas vivências, culturas e afetividades.

Partindo do pressuposto da necessidade de ofertarmos espaços e momentos nos quais as crianças possam expressar-se livremente, organizamos uma dinâmica de integração em que as crianças tiveram a oportunidade de manifestar suas corporeidades e imaginações. Para isso, 
disponibilizamos um baú contendo várias vestimentas de origem africanas, óculos de brinquedo, plumas, etc. Através dessa ação, almejávamos promover um ambiente descontraído, no qual as crianças pudessem utilizar os objetos para se apresentarem a toda a turma, além de retratarem um pouco de suas identificações e preferências. Durante essa minioficina, aproveitamos para registrar os momentos através de fotos, para posteriormente socializarmos nos blogs a serem construídos nos próximos encontros.

Seguindo essa perspectiva, no segundo encontro, com intuito de incentivar a produção de textos, propomos a construção de fôlderes de apresentação, então lhes ofertamos canetinhas, cartolinas, revistas, tesouras, canetas, entre outros materiais para a elaboração dos fôlderes. Sendo assim, solicitamos às crianças que expusessem nesse documento informações a respeito delas, ou seja, como elas se identificavam. Dessa forma, as crianças foram desafiadas a se representarem a partir de imagens que produzissem sentido em suas vidas.

Dentre os múltiplos momentos ocorridos durante essa ação, enfatizamos um caso primordial a ser relatado: uma aluna afrodescendente que possuía peso acima da sua estatura nos chamou atenção, pois em nenhuma revista ela se identificava, visto que não havia nas revistas imagens de famosos cujo perfil fosse semelhante ao dela. Em face do que foi exposto, vale denunciar que esses fatos afetam profundamente a autoestima das crianças, nesse caso, a menina, após não se identificar com nenhuma imagem, informou-nos que não faria a atividade e ficou extremamente chateada. Essa situação nos impulsionou a refletir, enquanto educadoras, sobre qual ação deveríamos efetivar naquele momento. Acreditamos que um primeiro passo é reconhecermos o quanto as mídias impressas disseminam estereótipos racistas e homogeneizadores, além disso, devemos denunciar a necessidade de os diversos meios de comunicação contemplarem todos os sujeitos e não reafirmarem somente um como o normal.

Nesse sentido, a partir desse fato, reiteramos a necessidade de questionarmos os padrões de beleza que são impostos para sociedade, pois eles não contemplam todas as pessoas. Ainda, nessa discussão, cabe destacar outras formas de discriminações - de gênero, raça e etnia - que perpassam pelo cotidiano escolar. Sobre esse debate Gonçalves e Silva (2005), aponta que

As formas de discriminação de qualquer natureza não têm seu nascedouro na escola, porém o racismo, as desigualdades e formas de discriminação perpassam por ali. Para que as instituições de ensino desempenhem a contento o papel de 
educar, é necessário que se constituam em espaço democrático. A escola tem o papel preponderante para a eliminação das discriminações e para a emancipação dos grupos discriminados, ao proporcionar acesso aos conhecimentos científicos, a registros culturais diferenciados, à conquista de racionalidade que rege as relações sociais e raciais [...] Para obter êxito, a escola e seus professores não podem improvisar. Têm que desfazer a mentalidade racista e discriminadora secular, superando o etnocentrismo europeu, reestruturando relações étnico-raciais, desalienando processos pedagógicos. (p. 14)

Ressaltamos, portanto, que é fundamental que os/as educadores(as) estejam atentos(as) para que, em suas práticas pedagógicas, bem como nas relações do dia a dia nas instituições educativas, valorizem e considerem todos os indivíduos, de tal forma que estes possam expressar suas corporeidades, afetividades, subjetividades e diferentes manifestações artísticas, a partir das suas singularidades.

Dando continuidade, cabe expor um breve diálogo que presenciamos durante a mesma oficina. Enquanto as crianças estavam elaborando o material, uma menina selecionou a foto da Beyonce, e a outra disse: "Você nem é negra, como vai pegar essa foto? E a menina respondeu: "Tá e daí, o que que tem, eu quero colocar".

Percebemos, com esse fato, como a mídia influencia a vida das crianças, direta ou indiretamente, expondo fotos de pessoas com estereótipos de beleza, nas quais grande parte da população negra não está contida, salvo as exceções, e atrizes ou cantoras famosas que se destacam ou que conseguem se colocar num padrão europeu e comercial. Nessa perspectiva, fica evidente a necessidade de ampliarmos esses padrões de beleza que nos são impostos.

Dando continuidade à realização dos trabalhos, iniciamos a construção dos blogs. Neles muitas crianças utilizaram informações que estavam presentes nos fôlderes de apresentação do Núcleo de Estudos Afro-Brasileiros (NEAB/UDESC) ${ }^{10}$. Em um dos blogs construídos, destacamos a seguinte informação

Título: "minha vida na net". Através do projeto Para Contar (Escrever) outras Histórias, integrante do programa Diversidade Étnica na Educação$\mathrm{NEAB} /$ UDESC, contarei a minha história de vida. Meu nome é V. L. A., minha mãe se chama L. e meu pai se chama I. E eu tenho 10 anos de idade e nasci no dia 02/10/1999 no hospital REGIONAL em São Jose as 21:30 h. Aos meus 2 meses viajei a São Paulo e minha mãe disse que foi divertido quando voltei minha vó estava morrendo de saudades e também logo fui para São Miguel visitar meus tios e fiquei por lá. E hoje que já estou com 10 anos e estudo na Escola de Educação Básica

\footnotetext{
${ }^{10}$ Objetivando demonstrar o que era um folder e qual era sua utilidade, levamos um fôlder do NEAB/UDESC para que as crianças pudessem manuseá-lo e dirimir possíveis dúvidas.
} 
Ildefonso Linhares e moro no bairro Carianos com meu pai que no dia 9/07 vai fazer 39 anos de idade.E essa história foi escrita no dia 07/07/2010. (Postagem no blog da Aluna V. L. A., quarta-feira, 7 de julho de 2010).

Verificamos que a maioria dos(as) participantes das oficinas já possuía cadastros nos ciberespaços, como e-mail, Orkut e MSN. Apenas a aluna que citamos acima era a única que tinha pouco contato com computador e não tinha e-mail. Pudemos verificar a importância de serem trabalhadas essas mídias através de um de seus depoimentos no blog:

Título: "curso" Eu gostei do curso pois aprendi coisas novas como: Mexer em computador e várias outras coisas com computador e eu gostei também por conhecer a prof M. e a prof P. e foi interessante pois fiz um blog e nele eu me divirto muito pois adoro escrever em computador. (Postagem no blog da Aluna V. L. A, terça-feira, 13 de julho de 2010).

Conforme Recuero (2003), para se abordar os blogs como grupos sociais, devemos também debater sobre a ideia de identidade que o indivíduo expressa. E o blog passa a ser uma representação individual no ciberespaço. Dessa forma, os blogs funcionam como representações do "eu", permitindo interação com os outros.

A questão da funcionalidade do blog pode ser verificada pelas participantes das oficinas:

Esse BLOG me ajudou em muita coisa por exemplo me ajudou a saber escrever certo sem erros de português mais uma pequena coisa importante que não posso esquecer fizemos um BLOG é a função de nos ajudar a contar e escrever outras histórias. Nós fizemos um FOLDER que ali nós mostramos do que nós gostamos isso que é um FOLDER se vc que está lendo a minha história. Só pra falar que é isso um folder se vc fizer um desses vc vai descobrir como é legal fazer um folder ainda mais como esse que nós fizemos no projeto da UDESC e NEAB. udesc significa: universidade do estado de Santa Catarina e neab significa: núcleo de estudo afro-brasileiros! esse projeto foi muito importante pra mim saber contar e escrever outras histórias adoro ves beijos. BY:E.! (Postagem no blog da aluna E., postado no dia quarta-feira, 14 de julho de 2010).

Eu aprendi com o projeto 'Neab/Udesc' a poder criar um blog para contar e escrever a minha história. Foi divertido até acabar as professoras são muito simpáticas, chamam-se M. e P.. Eu também gostei de poder fazer um folder de mim, eu acho que é só isso!!! Vou contar mais um pouco de mim: eu tenho muitas amigas uma delas são T., M. E., E. ,J. ,S., Y., A. L., C., I., I.,V., K., D. (Postagem no blog da aluna A. P., postado no dia quarta-feira, 14 de julho de 2010). 
Ainda, para Recuero, o layout do blog também traz a visão do "eu" dos indivíduos, pois a escolha das cores, as imagens e até a própria atualização ressaltam a ideia de que as identidades são construídas. E se os blogs são constantemente modificados, atualizados, reconstruídos, a identidade do sujeito também é.

Além disso, os blogs representam a pessoa, seus pensamentos e fatos de vida, traduzindo, assim, esse indivíduo através de elementos narrados. "E, é a partir desta representação que ele é conhecido e percebido pelos demais" (RECUERO, 2003, p.11).

Como podemos observar, as crianças sentiram-se muito à vontade para relatar passagens de suas vidas nos blogs, contando suas particularidades, preferências e sonhos, como exemplo:

Título: Minha vida. Através do projeto Para Contar (escrever) Outras Histórias, integrante do programa Diversidade Étnica na Educação NEAB/UDESC, contarei minha história.

Meu nome é A. P. Tenho 11 anos, moro no Carianos com minha mãe, meu padrasto e meu irmão. Meu pai deixou eu e minha mãe quando eu tinha 5 anos, um ano depois minha mãe se casou com meu padrasto.

Eu moro do lado da casa da minha vó e do meu vô matermos, eu tenho uma cachorra. O nome da minha cachorra e B. ela é muito fofa adora um colinho da mamãe.

Estou muito feliz de poder contar e escrever minha história de vida, e muito legal e interessante poder participar deste programa. Um dia eu vou me tornar uma secretaria executiva. Meu sonho é conhecer Justin Bieber um cantor adolescente muito famoso e muito lindo quase todas garotas gostam dele como eu !! (Postagem no blog da aluna A. P., postado quarta-feira, 7 de julho de 2010).

É pertinente divulgar que, após aplicar essas minioficinas com as crianças, repensamos nossas estratégias de trabalho, entre elas, a criação dos fôlderes de apresentação. Nas futuras oficinas, adaptaremos algumas estratégias objetivando tornar a intervenção mais didática e atrativa. Dessa maneira, salientamos a necessidade da conexão entre ação e reflexão, com intuito de proporcionar espaços e momentos lúdicos de aprendizagem.

Através da criação de $b \log s$, as crianças tiveram a oportunidade de experimentar o papel de "blogueiras", com a possibilidade de relatar suas histórias, lembranças, gostos e preferências musicais, ídolos, entre outras informações. Dessa forma, ofertamos momentos diferenciados, utilizando o espaço da sala de informática para realizar oficinas de inclusão digital, possibilitando aos participantes maiores contatos com as multimídias, bem como 
disponibilizamos períodos de diversão para brincarem com games e navegarem nos Orkuts, MSNs e e-mails. Nessa perspectiva, pretendemos contribuir para o desenvolvimento da autonomia das crianças, além de possibilitar um trabalho colaborativo e participativo, pois em todas as oficinas elas foram agentes de sua construção. Tinham como referência as bolsistas, enquanto mediadoras de conhecimentos, mas as verdadeiras autoras eram as próprias crianças, usando suas próprias histórias.

Além disso, cabe ressaltar que o desenvolvimento dessas ações nos impulsionou a elaborar uma oficina pedagógica sobre autoestima para integrar-se ao grupo de ações ofertadas pelo NEAB/UDESC. Essa contribuirá para o suporte às políticas públicas educacionais que visam à implantação e implementação da Lei 10.639/2003 ${ }^{11}$ e das Diretrizes Curriculares Nacionais para a Educação das relações Étnico-Raciais e para o Ensino e Cultura Africana e Afro-Brasileira, expandindo, assim, a ideia advinda de um projeto de extensão para outras crianças, jovens e adultos.

\section{CONSIDERAÇÕES FINAIS}

Ao finalizar nossas ações, percebemos a importância e necessidade de compreendermos cada sujeito na sua totalidade, reconhecendo suas preferências, histórias, culturas e seu jeito de ser. Nesse sentido, enfatizamos a valorização de todas as culturas e padrões de beleza, bem como a problematização em torno desses aspectos, com intuito de a escola e todos os ambientes sociais se tornarem um lugar de e para todos.

Sobre os padrões de beleza veiculados pela mídia, salientamos a necessidade de descontruirmos esses estereótipos, além de promovermos novas perspectivas, nas quais o belo não seja privilégio somente de determinada parcela da sociedade.

Por meio das vivências experienciadas no projeto Para Contar (Escrever) Outras Histórias, também constatamos o quanto são essenciais os planejamentos, registros e reflexões em torno das ações. Além disso, através da escrita do relatório de extensão, percebemos a dimensão das nossas ações, já que tivemos a oportunidade de conhecer um pouco mais a vida de personalidades catarinenses, vivenciarmos o cotidiano escolar e trabalharmos a ferramenta

\footnotetext{
${ }^{11}$ Após muitos debates e lutas, especialmente por parte dos movimentos sociais negros e pesquisadores(as) engajados(as) com a temática, no dia 09 de janeiro de 2003, foi sancionada a Lei Federal 10.639/03, a qual torna obrigatório o ensino de história e cultura africana e afro-brasileira em todas as instituições de ensino, alterando assim a LDB/96.
} 
dos blogs com ambos os grupos, fazendo com que vislumbrássemos a conexão essencial entre a teoria e a prática.

Assim, almejamos utilizar as tecnologias de informação e comunicação na perspectiva de inserir os sujeitos digitalmente, possibilitando, com isso, a democratização do acesso às mídias que estão disponíveis, mas que muitas vezes não são utilizadas com o papel de inclusão social.

Para finalizar, vale reiterar a importância de reconhecermos as ações de extensão enquanto produtoras de conhecimentos.

\section{REFERÊNCIAS}

BELlONI, Maria Luiza. O que é Mídia. 2.ed. São Paulo: Autores Associados, 2005, 100 p.

BRASIL. Ministério da Educação. Diretrizes Curriculares Nacionais para a Educação das Relações Étnicorraciais e para o Ensino de História e Cultura Africana e Afrobrasileira. Brasília: MEC, 2005.

GOMES, Nilma Lino. A questão racial na escola: desafios colocados pela implementação da Lei 10.639/03. In: MOREIRA, Antônio Flávio Barbosa; CANDAU, Vera Maria (Org.).

Multiculturalismo: diferenças culturais e práticas pedagógicas. Petrópolis: Vozes, 2008, v., p. 67-89.

PRIMO, Alex. Blogs e seus gêneros: Avaliação estatística dos 50 blogs mais populares em língua portuguesa. In: XXXI Congresso Brasileiro de Ciências da Comunicação - Intercom 2008, Natal. Anais, 2008. Disponível em: http://www6.ufrgs.br/limc/PDFs/50_blogs.pdf. Acesso em 21 de março de 2011.

RECUERO, Raquel da Cunha. Weblogs, Webrings E Comunidades Virtuais. Disponível em: http://www.pontomidia.com.br/raquel/webrings.pdf. Acesso em 21 de março de 2011.

SCHONINGER, R. R. Z. V. Blogs de Escolas: Possibilidades de construção de Ambiências Comunicativas. 2010. 93 f. Dissertação (Mestrado em Educação) - Universidade do Estado de Santa Catarina, Santa Catarina, 2010. 